\title{
Cultivar and Seasonal Effects on Seed Oil Content and Fatty acid Composition of Cucumber As a Potential Industrial Crop
}

\author{
Joyce W. Ngure' ${ }^{1}$, Chunyan Cheng', Shuqiong Yang, Qunfeng Lou, Ji Li, Chuntao Qian, \\ Jie Chen, and Jinfeng Chen ${ }^{2}$ \\ State Key Laboratory for Crop Genetics and Germplasm Enhancement, College of Horticulture, \\ Nanjing Agricultural University, Nanjing 210095, China
}

\begin{abstract}
Additional IndeX words. Cucumis sativus, linoleic, palmitic, oleic, stearic, linolenic, spring, autumn
Abstract. Cucumber (Cucumis sativus) seed oil has the potential for use as an edible oil and as a pharmaceutical, cosmetic, insecticidal, and industrial product. In this study, we investigated, for the first time, the effect of cultivar and season on seed number, oil content, and fatty acid profiles as well as their proportions in different cucumber cultivars. We examined the effects of spring and autumn seasons on seed oil content and fatty acid composition in 46 cucumber cultivars and one wild species of cucumber $(C$. anguria) grown in greenhouse experiments in 2013 and 2014 . Seed oil was determined using the Soxhlet method and fatty acids using the gas chromatography-mass spectrometry method. Seed oil content in the cucumber seeds ranged from $41.07 \%$ in 'Hazerd' to $29.24 \%$ in 'Lubao' while $C$. anguria had 23.3\% Fatty acids detected were linoleic (C18:2), palmitic (C16:0), oleic (C18:1), stearic (C18:0), linolenic (C18:3), behenic (C22:0), arachidic C20:0), lignoceric (C24:0), eicosenoic (C20:1), palmitoleic (C16:1), and myristic (C14:0), among other unidentified fatty acids. The results showed significant effects of cultivar genotype, growing season, and interactions on the variables examined. The content of seed oil and fatty acids differed significantly among the cultivar genotypes. Spring-grown cucumbers had higher quantities of oil than the autumn-grown cucumbers. The content of fatty acids (mainly palmitic, palmitoleic, stearic, oleic, eicosenoic, and lignoceric) also was higher in spring. In autumn there were more seeds, and higher linoleic, linolenic, and other unspecified fatty acids. The higher the oleic acid content the lower was the linoleic acid indicating a strong negative relationship in these two fatty acids. The higher the seed oil content the higher was linoleic and oleic indicating a positive relationship between the seed oil and the two fatty acids. Results of this study provide important information applicable in improving management and production of cucumber seed oil especially considering its versatility in uses. Furthermore, the wide range of fatty acids found in the studied cucumber cultivars could be used in the production of novel industrial oils through genetic engineering.
\end{abstract}

Cucumber fruit is used in treating human constipation and indigestion, and in cooling the body in summer. Young fruit are preferred for pickling while seed kernels are used in confectionary (Saboo et al., 2013). Cucumbers have potential medicinal uses and are reported to have pharmacological properties $(\mathrm{Ng}, 1993)$. Traditionally, cucumber fruit has been used as a diuretic, antipyretic agent, in treatment of skin diseases (Mallik et al., 2013) and in alcohol detoxification (Tadayyon, 2013). The leaves and roots are used to treat diarrhea and dysentery while the stem is used to treat gonorrhea and lupus (Yang and Walters, 1992). The fruit is demulcent, seeds are cooling, tonic, and anthelmintic, and leaves are used to treat throat infections (Rahman et al., 2008). The fruit is anti-inflammatory, antidiabetic, and an abortifacient (Heidari et al., 2012; Mootoosamy and Fawzi, 2014). Fruit are laxative, astringent, and febrifuge, and are used to treat hepatitis, bronchitis, asthma, dyspepsia, leprosy, piles, menstrual disorder, dropsy, coughs, hoarseness of voice, eye diseases, and scorpion (Androctonus amoreuxi) sting, and are used as a hair tonic. Cucumber extracts are larvicidal in mosquito [Anopheles gambiae (Rahuman and Venkatesan, 2008)], insecticidal to the red flour beetle [Tribolium castaneum (Mostafa et al., 2012)], repellant to ants [Pachycondyla verenae (Chaudhari, 2014)], and kill cockroaches [Periplaneta americana (Van Luijk, 2004)]. The seed is used to treat typhoid in Iran (Souri et al., 2008). Crushed and compressed

${ }^{1}$ These authors contributed equally to this work.

${ }^{2}$ Corresponding author. E-mail: jfchen@njau.edu.cn. seeds when applied on the skin prevent wrinkles (Pieroni et al., 2004). Seeds are narcotic and the seed oil is used in treating rheumatism (Mallik et al., 2013).

Plant seed oils are included in cosmetic products due to their high fatty acid composition (Vermaak et al., 2011). Topical application of essential fatty acids prevent and counteract dry seborrhoeic skin conditions and inflammation (Muller et al., 2007). Topical application of linoleic acid reduces inflammatory acne lesions (Magin et al., 2006) which could explain cucumbers' efficiency in skin care.

Cucumber seed oil contains polyunsaturated fatty acids which alleviate cardiovascular diseases, some cancers, and arthritis (Ursin, 2003). Linoleic acid and alpha-linolenic acid are essential fatty acids that cannot be synthesized by the body and must be obtained through daily dietary intake. In the human body, linoleic acid is metabolized to arachidonic acid (C20:4) while alphalinolenic acid is metabolized to eicosapentaenoic acid (C20:5) and docosahexaenoic acid (C22:6), which are hypolipidemic, antithrombotic, antiarrhythmic, antihypertensive, and antiinflammatory (Simopoulos, 1991). Cucumber seeds contain oleic, which is a diuretic (Wright et al., 2007) that reduces blood pressure (Terés et al., 2008) and also prevents cancer (Waterman and Lockwood, 2007). Cucumber seed oil decreases cholesterol and hence can reduce cardiovascular diseases (Achu et al., 2008).

Genotype and environmental conditions affect oil content and fatty acid compositions in oilseed crops. Helianthus annuus seeds showed reduced oil and oleic acid quantity in autumn as 


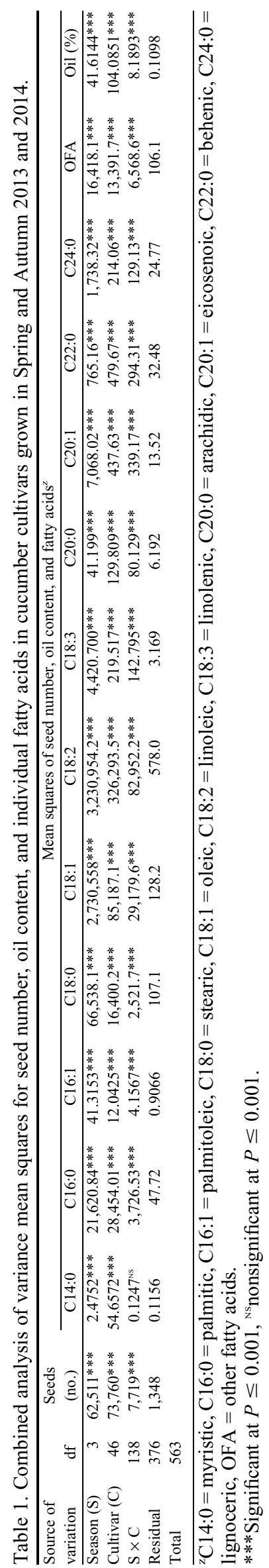

compared with spring. However, palmatic and linoleic increased more in autumn than in spring due to differences in temperature conditions (Fayyaz-ul-Hasan and Ahmad, 2003; Ghulam et al., 2006). Low moisture content in H. annuus seeds produced higher oleic acid during the dry season than in the rainy season (Sukkasem et al., 2013). Brassica napus cultivars had higher oil content in spring than in winter (Amir et al., 2012). Salinity stress increased oleic acid while decreasing linoleic and linolenic in Carthamus tinctorius. It is therefore important to understand the effects of genotype and environment, and their interactions, on seed oil and fatty acid production and quantity.

In this paper, we report the potential use of cucumber as a source of oil that can be used as an edible oil, a pharmaceutical product, a cosmetic ingredient, and an insecticide as well as for other novel industrial uses. We investigated, for the first time, the effect of cucumber cultivar and season on seed number, oil content, and fatty acid profiles. We also investigated the proportions of seed number, oil content, and fatty acid in different cucumber cultivars.

The results will inform researchers on cucumber cultivars to select for breeding and genetic engineering for desired amounts of seeds, oil, and fatty acids. Information on the seasonal variations in seeds, oil, and fatty acid compositions will ensure that the environmental effect is understood to guide management and optimal oil and fatty acid production; in naturally or genetically derived oils.

\section{Materials and Methods}

The experimental site was at Jiangpu experimental farm located in Nanjing Agricultural University, Jiangsu Province of China (lat. $32^{\circ} 3^{\prime} 4.96^{\prime \prime} \mathrm{N}$, long. $118^{\circ} 36^{\prime} 38.78^{\prime \prime} \mathrm{W}$ ). The study was carried out during the growing seasons of Autumn and Spring 2013 and 2014. Low and high temperatures in the spring growing season were March $\left(3\right.$ to $\left.15^{\circ} \mathrm{C}\right)$, April $\left(9\right.$ to $\left.21^{\circ} \mathrm{C}\right)$, May $\left(15\right.$ to $\left.26^{\circ} \mathrm{C}\right)$, and June $\left(19\right.$ to $\left.30^{\circ} \mathrm{C}\right)$. The autumn season was August $\left(25\right.$ to $\left.33^{\circ} \mathrm{C}\right)$, September $\left(18\right.$ to $\left.29^{\circ} \mathrm{C}\right)$, October (12 to $23{ }^{\circ} \mathrm{C}$ ), and November $\left(5\right.$ to $\left.17{ }^{\circ} \mathrm{C}\right)$. The soil at the experimental site is a clay loam.

The experimental design was a completely randomized block design where mature seeds of 46 cucumber cultivars and one wild species of cucumber were selected from the laboratory germplasm bank. The seeds were first germinated in small tubes and then transplanted into the experimental greenhouses with drip irrigation and polythene mulch. Five replicates of each cultivar were transplanted. The cultivars were conventionally grown and a blended fertilizer with micronutrients $(12 \mathrm{~N}-5.2 \mathrm{P}-$ $10 \mathrm{~K})$ was applied at $30 \mathrm{~g}$ for each plant every 3 weeks. The plants were supported with strings and pruned to a single stem. Fertilization of the flowers was done manually for three fruit on each plant and any other fruit growing was removed to ensure optimal seed filling of the fertilized fruit.

Seed harvesting was done when the cucumber fruit was mature and had turned yellow and soft, at 30 and $45 \mathrm{~d}$ after fertilization in spring and autumn, respectively. Thus, harvesting in spring was at the end of June while autumn fruits were harvested in mid-November. Consequently, the cucumber fruit from fertilization to maturity in spring had approximate average temperatures of 19 to $30{ }^{\circ} \mathrm{C}$ and in autumn 12 to $23^{\circ} \mathrm{C}$. Seeds were then extracted from the fruit, washed, and sun dried. The seeds from individual fruit were counted, recorded, and kept in 


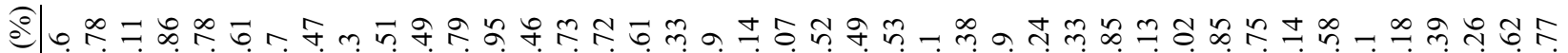

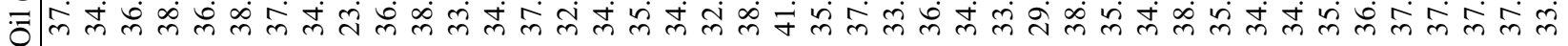

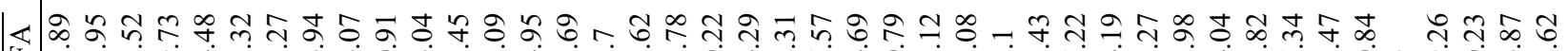

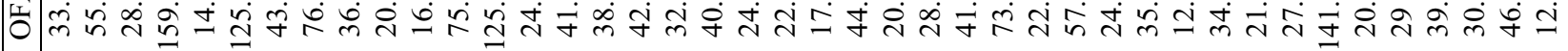

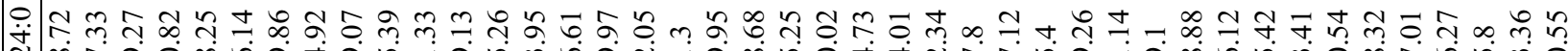
Ű்

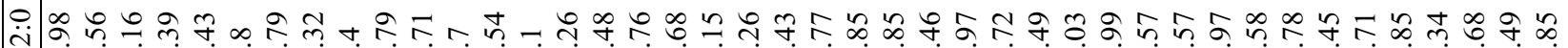
ปึ의

تే Uิป

융

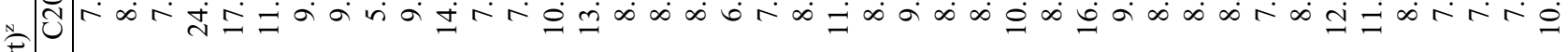
경

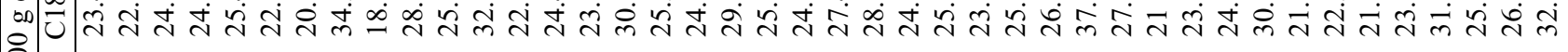
कo

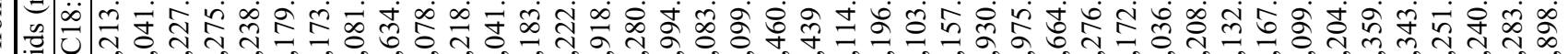

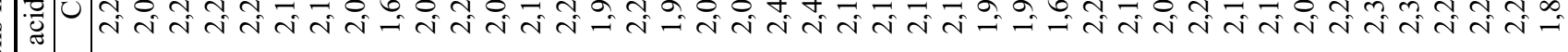

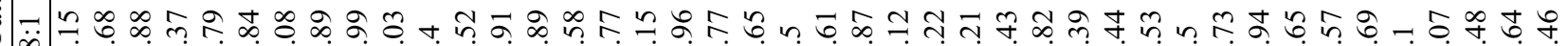

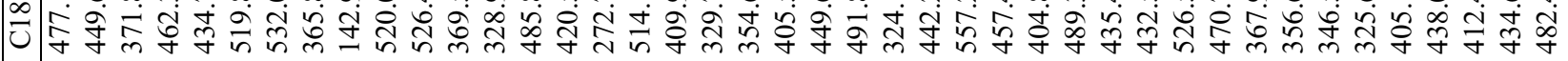

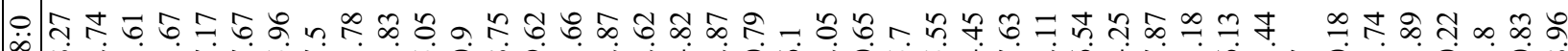
U一兀

चี

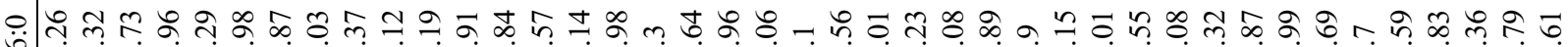

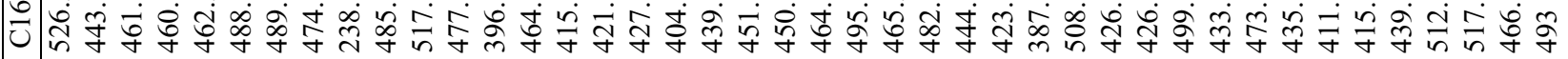

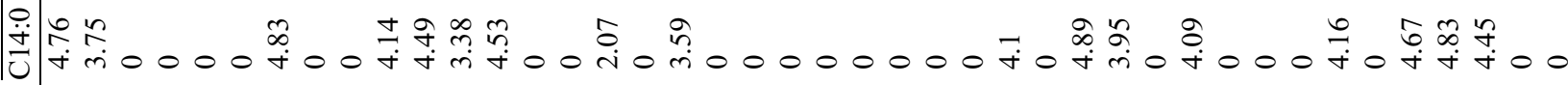

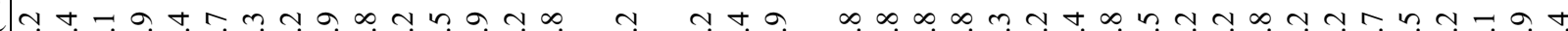

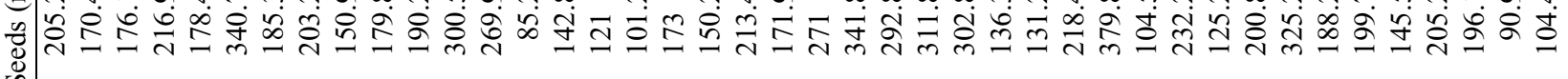
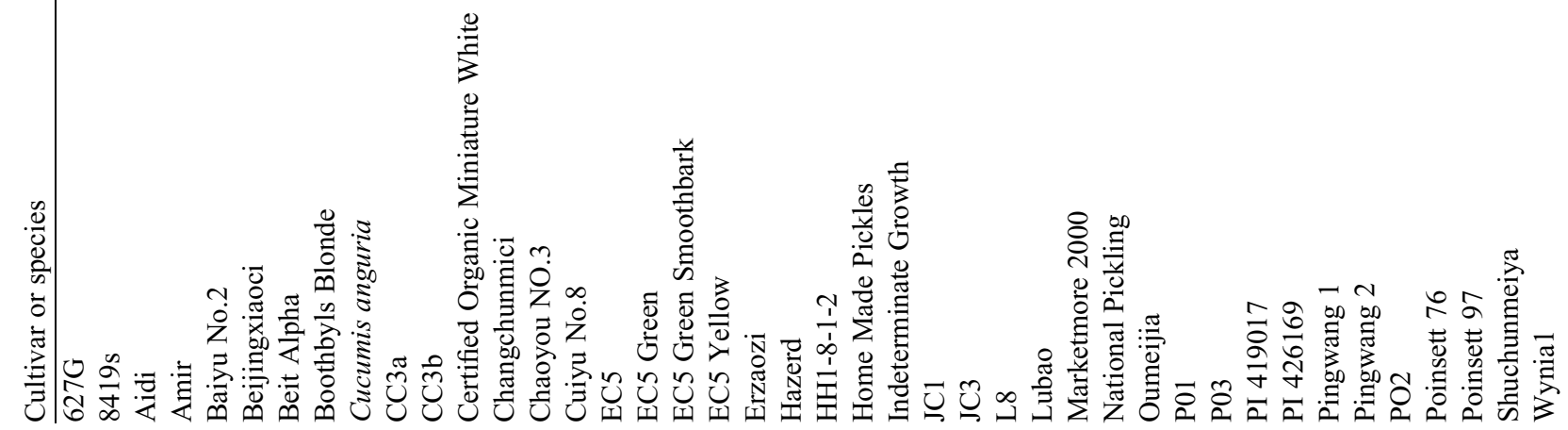


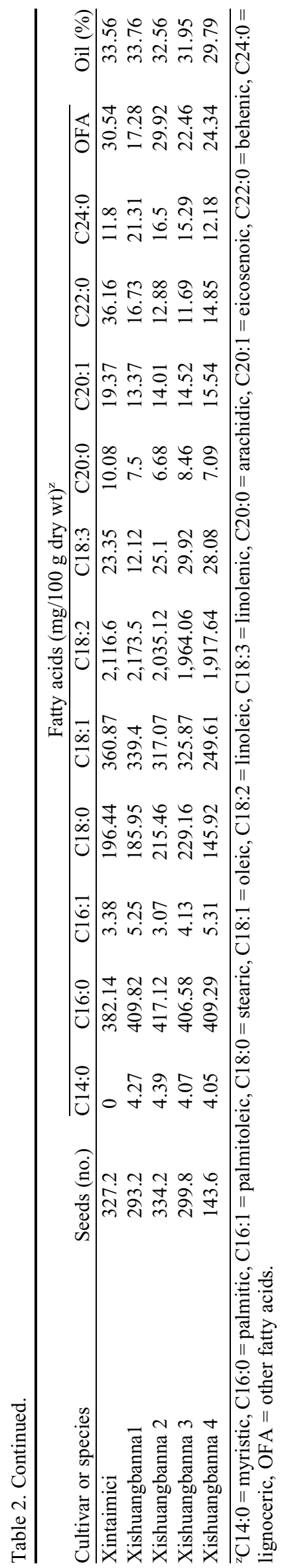

separate bags. The seeds were then selected from each bag and bulked in a separate bag for each cultivar for seed oil and fatty acid extraction and analysis.

Seed sample preparations for each cultivar were obtained from the bulked seeds and dried in an oven at $80^{\circ} \mathrm{C}$ for $16 \mathrm{~h}$ to constant moisture. The Ultra-Turrax machine (Ika-Werke, Staufen, Germany) was used to grind seed samples in triplicates for seed oil extraction as well as fatty acid methylation. The grinder was washed with ethanol after each sample preparation to avoid contamination.

Seed oil extraction was determined according to the Association of Official Agricultural Chemists (AOAC) method (1990). The extraction was performed with diethyl ether solvent. An automated Soxhlet extractor (Universal Extraction System B-811/B-811 LSV; Büchi Labortechnik, Flawil, Switzerland) was used to extract cucumber seed oil. To achieve this, $10 \mathrm{~g}$ of ground seed powder was put in a folded filter paper and placed inside a $250-\mathrm{mL}$ extractor device. The sample was extracted for $8 \mathrm{~h}$ at the solvent's boiling point temperature. The proportion of diethyl ether was $150 \mathrm{~mL}$ in a $250-\mathrm{mL}$ Soxhlet flask at $60{ }^{\circ} \mathrm{C}$. The sample was put in an oven for $3 \mathrm{~h}$ at $105^{\circ} \mathrm{C}$ and then weighed again to get the oil content:

$$
\% \text { Oil }=\frac{\begin{array}{c}
\text { weight of sample before extraction }- \\
\text { weight of sample after extraction }
\end{array}}{\text { weight of sample before extraction }} \times 100
$$

Ground powder of $1000 \mathrm{mg}$ of each cultivar from the bulked seeds was each immersed in petroleum ether: absolute ether in the ratio of $3 \mathrm{~mL}: 3 \mathrm{~mL}$ in a $10-\mathrm{mL}$ centrifuge tube with a stopper which was vortexed and left for $16 \mathrm{~h}$ at room temperature. The crude oil supernatant was then extracted and put in a $10-\mathrm{mL}$ centrifuge tube where $2 \mathrm{~mL}$ of $\mathrm{KOH}$ in methanol $(0.5 \mathrm{~mol}$ $\mathrm{Na}$ per liter of methanol) was added for methyl esterification. Samples were then vigorously shaken for $1 \mathrm{~min}$ at room temperature, left for $2 \mathrm{~h}$ when $10 \mathrm{~mL}$ distilled water was added and left for another $1 \mathrm{~h}$ (AOAC, 1990). Finally, the supernatant was transferred into the auto sampler vials for gas chromatography-mass spectrometry (GC-MS) analysis in triplicates for each cultivar.

The GC-MS analysis of the methyl esters of the fatty acids $(2 \mu \mathrm{L})$ was performed in a 7890 Series gas chromatograph (Agilent Technologies, Little Falls, DE) equipped with a flame-ionizing detector and a fused silica capillary column (HPINNOWAX, 19091N-133, $30.0 \mathrm{~m} \times 250 \mu \mathrm{m} \times 0.25 \mu \mathrm{m}$; Agilent). This process was conducted at an oven temperature of $180{ }^{\circ} \mathrm{C}$, which was then raised to $210{ }^{\circ} \mathrm{C}$ at a rate of $5.0{ }^{\circ} \mathrm{C} \cdot \mathrm{min}^{-1}$ and then kept at $205{ }^{\circ} \mathrm{C}$ for $1 \mathrm{~min}$. The oven temperature was raised to $230{ }^{\circ} \mathrm{C}$ at a rate of $3.0^{\circ} \mathrm{C} \cdot \mathrm{min}^{-1}$ and then kept for $4 \mathrm{~min}$. The injector and detector temperatures were 250 and $300{ }^{\circ} \mathrm{C}$, respectively. The carrier gas was nitrogen $(99.999 \%)$ at a flow rate of $29.2 \mathrm{~mL} \cdot \mathrm{min}^{-1}$ and Constant column was $0.8 \mathrm{~mL} \cdot \mathrm{min}^{-1}$.

Peak identification was performed by comparing the relative retention times with those of a commercial standard mixture of FAME (Sigma-Aldrich, St. Louis, MO). The fatty acid quantity of linoleic, palmitic, oleic, stearic, linolenic, behenic, arachidic, lignoceric, eicosenoic, palmitoleic, myristic, and other fatty acids were determined using a computing integrator and recorded as a percentage of total fatty acids. Fatty acid percentages were then converted to milligrams per $100 \mathrm{~g}$ to get the amount of each individual fatty acid. 
Data were analyzed using GenStat statistical package (VSN International, Hemel Hempstead, UK) using a two-way combined analysis of variance (ANOVA) for two seasons (spring and autumn) both in 2013 and 2014. All the effects were considered random for seed number, oil content, fatty acids, and the interaction of cultivars and seasons. Effects were considered statistically significant at $P \leq 0.01$. Correlation was done using Spearman's correlation as provided by GenStat. Season means were further compared pairwise for significance using the Bonferroni test.

\section{Results}

Results of the combined ANOVA indicated significant variations for the four seasons (Spring and Autumn 2013 and 2014) in seed numbers, oil content as well as all the fatty acids. Results were also highly significant for the 46 cultivars and the wild species in all the assessed parameters. Significant effects were also observed in the season and cultivar interaction for all parameters except for myristic acid (C14:0), cultivar, and season interaction at $P \leq 0.001$ (Table 1 ).

The fatty acids found in cucumber were linoleic, palmitic, oleic, stearic, linolenic, behenic, arachidic, lignoceric, eicosenoic, palmitoleic, myristic, and other fatty acids. Seed oil was significantly different in the study cultivars as shown in Table 1. 'Hazerd' had the highest seed oil $(41.07 \%)$ while the wild species (C. anguria) had the lowest at $23.3 \%$. The lowest of the cucumber cultivars was Lubao at 29.24\%. 'National Pickling' cucumber had the highest seed number with 379.8 seeds and the lowest was 'Chaoyou NO.3' with 85.2 seeds. Myristic had significant variation in the study cultivars with the highest being in Marketmore 2000 (4.89 mg/100 g) and many cultivars did not have detectable amounts. The highest quantity of palmitic was in '627G' (526 mg/100 g) and lowest in 'Xintaimici' (382 $\mathrm{mg} / 100 \mathrm{~g})$, although $C$. anguria had a lower measure at $238 \mathrm{mg} /$ $100 \mathrm{~g}$. Palmitoleic was $6.28 \mathrm{mg} / 100 \mathrm{~g}$ in 'CC3a' and in
'Pingwang' was $2.02 \mathrm{mg} / 100 \mathrm{~g}$, while C. anguria had 1.63 $\mathrm{mg} / 100 \mathrm{~g}$ of the fatty acid. 'EC5 Green' with $292.62 \mathrm{mg} / 100 \mathrm{~g}$ had the highest stearic while 'Xishuangbanna' and $C$. anguria had 145.92 and $113.78 \mathrm{mg} / 100 \mathrm{~g}$ of the fatty acid, respectively (Table 2).

In Table 2 oleic acid ranged from $557.21 \mathrm{mg} / 100 \mathrm{~g}$ in 'JC3' to $249.61 \mathrm{mg} / 100 \mathrm{~g}$ in 'Xishuangbanna', and C. anguria had $142.99 \mathrm{mg} / 100 \mathrm{~g}$. Highest amount of linoleic was $2460.55 \mathrm{mg} /$ $100 \mathrm{~g}$ in 'Erzaozi', while the lowest was in 'Lubao' at 1664.42 $\mathrm{mg} / 100 \mathrm{~g}$. C. anguria had $1634.63 \mathrm{mg} / 100 \mathrm{~g}$. Linolenic acid ranged from $37.06 \mathrm{mg} / 100 \mathrm{~g}$ in 'Marketmore 2000' to 12.12 $\mathrm{mg} / 100 \mathrm{~g}$ in 'Xishuangbannal'. Arachidic ranged from 24.14 $\mathrm{mg} / 100 \mathrm{~g}$ in 'Amir' to $6.68 \mathrm{mg} / 100 \mathrm{~g}$ in 'Xishuangbanna 2'. $C$. anguria had $5.36 \mathrm{mg} / 100 \mathrm{~g}$. Highest amount of eicosenoic was $31.6 \mathrm{mg} / 100 \mathrm{~g}$ in 'Pingwang 2' and least was $5.07 \mathrm{mg} / 100 \mathrm{~g}$ in 'PI 426169'. Behenic acid ranged from 'Xintaimici' (36.16 mg/ $100 \mathrm{~g}$ ) to 'Marketmore 2000' (7.03 mg/100 g), while lignoceric varied from $21.31 \mathrm{mg} / 100 \mathrm{~g}$ in 'Xishuangbannal' to $5.4 \mathrm{mg}$ / $100 \mathrm{~g}$ in 'Lubao'. Other fatty acids were highest in 'Amir' $(159.73 \mathrm{mg} / 100 \mathrm{~g})$ and lowest in 'Wynial' at $12.62 \mathrm{mg} / 100 \mathrm{~g}$.

Correlations were tested for the different parameters as shown in Table 3. Palmitic acid had a positive relation with seed oil and fatty acids, including palmitoleic, stearic, oleic, linolenic, arachidic, and eicosenoic. Palmitoleic had also a positive relation with seed oil and fatty acids, including stearic, oleic, arachidic, and lignoceric. Stearic had a positive relation with seed oil and oleic acid.

Oleic had a strong negative relation with linoleic and a positive correlation with seed oil, arachidic, eicosenoic, and lignoceric. Linoleic had a strong positive relationship with seed oil. Linolenic had a positive relation with seed oil as well as a negative relation with arachidic. Arachidic was positively related to eicosenoic while eicosenoic had a positive correlation with lignoceric. Lignoceric had a weak positive relation with seed oil.

Table 4 shows the season $\times$ cultivar interaction which is significant at $P \leq 0.001$ for all measured variables except

Table 3. Spearman's rank correlation $(r)$ of seed number, oil content, and fatty acids in cucumber cultivars.

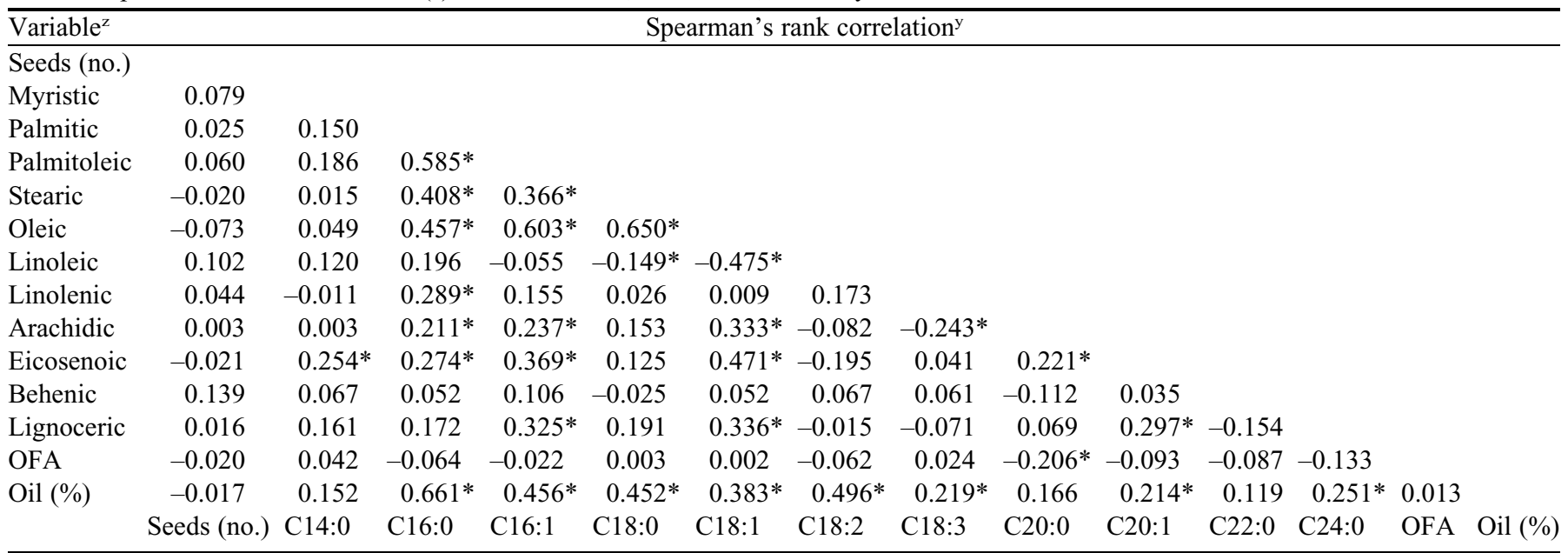

${ }^{\mathrm{z}} \mathrm{C} 14: 0=$ myristic, $\mathrm{C} 16: 0=$ palmitic, $\mathrm{C} 16: 1=$ palmitoleic, $\mathrm{C} 18: 0=$ stearic, $\mathrm{C} 18: 1=$ oleic, $\mathrm{C} 18: 2=$ linoleic, $\mathrm{C} 18: 3=$ linolenic, $\mathrm{C} 20: 0=$ arachidic, $\mathrm{C} 20: 1=$ eicosenoic, C22:0 = behenic, C24:0 = lignoceric, OFA = other fatty acids.

$\mathrm{y}_{ \pm} 1$ is an exact perfect positive or negative linear relationship, $\geq \pm 0.70$ or higher very strong positive or negative relationship, \pm 0.40 to \pm 0.69 strong positive or negative relationship, \pm 0.30 to \pm 0.39 moderate positive or negative relationship, \pm 0.20 to \pm 0.29 weak positive or negative relationship, \pm 0.01 to \pm 0.19 no or negligible relationship.

*Positive or negative correlations between variables. 
Table 4. Comparison of Spring and Autumn 2013 and 2014 interaction means for season and cultivar in seed number, oil content, and individual fatty acids in cucumber cultivars.

\begin{tabular}{|c|c|c|c|c|c|c|c|c|c|c|c|c|c|c|c|c|}
\hline \multirow[b]{4}{*}{ Cultivar or species } & \multicolumn{16}{|c|}{ aber, oil content, and fatty acids $(\mathrm{mg} / 100 \mathrm{~g}$ dry } \\
\hline & \multicolumn{4}{|c|}{ Seeds (no.) } & \multicolumn{4}{|c|}{ C14:0 } & \multicolumn{4}{|c|}{ C16:0 } & \multicolumn{4}{|c|}{ C16:1 } \\
\hline & \multicolumn{2}{|c|}{ Spring } & \multicolumn{2}{|c|}{ Autumn } & \multicolumn{2}{|c|}{ Spring } & \multicolumn{2}{|c|}{ Autumn } & \multicolumn{2}{|c|}{ Spring } & \multicolumn{2}{|c|}{ Autumn } & \multicolumn{2}{|c|}{ Spring } & \multicolumn{2}{|c|}{ Autumn } \\
\hline & 2013 & 2014 & 2013 & 2014 & 2013 & 2014 & 2013 & 2014 & 2013 & 2014 & 2013 & 2014 & 2013 & 2014 & 2013 & 2014 \\
\hline $627 \mathrm{G}$ & 177.7 & 180.3 & 229.3 & 233.3 & 4.49 & 4.77 & 4.61 & 5.19 & 502.25 & 541.22 & 528.37 & 533.22 & 5.52 & 6.6 & 6.14 & 6.75 \\
\hline 8419 & 159.7 & 148.7 & 183.3 & 190 & 3.6 & 3.71 & 3.57 & 4.13 & 460.19 & 436.86 & 434.39 & 441.86 & 4.58 & 4.72 & 1.62 & 2.33 \\
\hline Aidi & 166.7 & 138 & 193 & 206.7 & 0 & 0 & 0 & 0 & 488.17 & 475.3 & 437.63 & 445.83 & 4.59 & 5.02 & 4.71 & 5.33 \\
\hline Amir & 234 & 144 & 243 & 246.7 & 0 & 0 & 0 & 0 & 500.06 & 486.16 & 425.99 & 431.61 & 6.91 & 6.22 & 2.12 & 2.54 \\
\hline Baiyu No.2 & 180 & 136.7 & 197 & 200 & 0 & 0 & 0 & 0 & 431.5 & 618.83 & 397.66 & 401.18 & 4.82 & 4.08 & 4.33 & 5.03 \\
\hline Beijingxiaoci & 331.3 & 367 & 331 & 333.3 & 0 & 0 & 0 & 0 & 557.89 & 485.17 & 452.73 & 460.13 & 7.31 & 6.02 & 5.42 & 5.83 \\
\hline Beit Alpha & 187.7 & 173.3 & 187 & 193.3 & 4.79 & 4.65 & 4.53 & 5.34 & 496.69 & 507.85 & 474.07 & 480.89 & 6.02 & 6.8 & 4.99 & 5.42 \\
\hline BoothbylsBlonde & 203.3 & 119.3 & 245 & 245.3 & 0 & 0 & 0 & 0 & 426.32 & 464.53 & 498.3 & 506.96 & 4.86 & 7.03 & 3.76 & 4.47 \\
\hline Cucumis anguria & 155.7 & 163.3 & 141.3 & 143.3 & 0 & 0 & 0 & 0 & 216.03 & 217.82 & 256.18 & 263.47 & 0.22 & 3.6 & 1.04 & 1.64 \\
\hline $\mathrm{CC} 3 \mathrm{a}$ & 106.7 & 237.7 & 188.3 & 186.7 & 3.93 & 3.96 & 3.88 & 4.8 & 473.06 & 487.76 & 485.97 & 493.69 & 5.89 & 6.75 & 5.93 & 6.54 \\
\hline $\mathrm{CC} 3 \mathrm{~b}$ & 125.7 & 145.3 & 241.3 & 248.7 & 4.29 & 4.73 & 4.21 & 4.72 & 537.5 & 550.46 & 485.54 & 495.24 & 6.19 & 7.49 & 4.92 & 5.53 \\
\hline Cerified organic miniature white & 325.3 & 293.3 & 287 & 296.3 & 3.36 & 3.03 & 3.19 & 3.94 & 493.41 & 427.97 & 492.15 & 498.12 & 6.61 & 4.75 & 4.68 & 5.49 \\
\hline Changchunmici & 240.7 & 230.7 & 305 & 303.3 & 4.28 & 4.38 & 4.26 & 5.2 & 446.44 & 408.77 & 362.52 & 369.62 & 4.28 & 4.38 & 2.95 & 3.35 \\
\hline Chaoyou No.3 & 92.7 & 106 & 65.7 & 76.7 & 0 & 0 & 0 & 0 & 441.43 & 506.1 & 451.69 & 459.04 & 2.29 & 6.69 & 4.54 & 5.05 \\
\hline Cuiyu No.8 & 150 & 121.7 & 149.7 & 150 & 0 & 0 & 0 & 0 & 482.81 & 488.69 & 340.28 & 348.79 & 5.98 & 4.73 & 3.55 & 4.07 \\
\hline EC5 & 111.7 & 190.7 & 88.3 & 93.3 & 2.21 & 2.01 & 1.83 & 2.21 & 446.3 & 382.15 & 425.6 & 433.88 & 4.87 & 3.69 & 3.76 & 4.39 \\
\hline EC5 Green & 101 & 62.3 & 116.3 & 125 & 0 & 0 & 0 & 0 & 458.08 & 427.82 & 408.02 & 415.28 & 5.13 & 4.29 & 4.25 & 4.76 \\
\hline EC5 Green smoothbark & 101 & 82.7 & 241.7 & 266.7 & 3.68 & 3.49 & 3.54 & 3.64 & 458.08 & 382.19 & 385.99 & 392.3 & 5.13 & 4.44 & 3.54 & 4.06 \\
\hline EC5 Yellow & 101 & 286.7 & 102.3 & 110.7 & 0 & 0 & 0 & 0 & 458.08 & 407.76 & 442.56 & 451.44 & 5.13 & 3.64 & 3.01 & 3.54 \\
\hline Erzaozi & 183.3 & 270.7 & 197.7 & 202 & 0 & 0 & 0 & 0 & 462.53 & 464.46 & 436.16 & 441.1 & 4.15 & 4.32 & 4.34 & 5.06 \\
\hline Hazerd & 61.7 & 238.3 & 188.3 & 199.3 & 0 & 0 & 0 & 0 & 296.14 & 511.88 & 492.93 & 499.47 & 0.28 & 6.87 & 5.47 & 6 \\
\hline HH1-8-1-2 & 182 & 336.7 & 283.7 & 281.7 & 0 & 0 & 0 & 0 & 449.7 & 514.84 & 444.53 & 449.17 & 5.27 & 5.1 & 4.04 & 4.65 \\
\hline Home Made pickles & 366.7 & 215 & 388.7 & 396.7 & 0 & 0 & 0 & 0 & 463.63 & 529.96 & 490.14 & 496.33 & 5.84 & 6.06 & 4.46 & 5.17 \\
\hline Indeterminate growth & 266.7 & 322.3 & 289 & 293 & 0 & 0 & 0 & 0 & 472.54 & 470.57 & 452.54 & 465.27 & 5.13 & 4.92 & 4.51 & 5.57 \\
\hline $\mathrm{JC} 1$ & 316.7 & 287.3 & 318.7 & 324.7 & 0 & 0 & 0 & 0 & 501.36 & 83.49 & 467.81 & 475.65 & 6.07 & 6.28 & 5.42 & 6.14 \\
\hline $\mathrm{JC} 3$ & 246.7 & 243.3 & 354.3 & 366.7 & 0 & 0 & 0 & 0 & 470.81 & 439.67 & 430.59 & 438.48 & 6.57 & 5.12 & 5.05 & 5.76 \\
\hline L8 & 139.7 & 125 & 137.3 & 143.3 & 4.12 & 3.76 & 3.74 & 4.77 & 463.53 & 418.28 & 404.67 & 409.1 & 6.06 & 5.96 & 4.16 & 4.56 \\
\hline Lubao & 140 & 93.3 & 142 & 149.7 & 0 & 0 & 0 & 0 & 363.83 & 363.83 & 407.73 & 413.21 & 5.48 & 5.49 & 3.92 & 4.42 \\
\hline Marketmore2000 & 237.7 & 237.3 & 198.7 & 200 & 4.78 & 4.73 & 4.65 & 5.39 & 522.83 & 494.01 & 504.35 & 510.84 & 2.72 & 6.92 & 4.89 & 5.31 \\
\hline National Pickling & 228.3 & 329.3 & 478 & 483.3 & 3.69 & 3.78 & 3.7 & 4.63 & 435.15 & 432.21 & 412.8 & 426.03 & 3.46 & 5.38 & 3.92 & 4.57 \\
\hline Oumeijia & 106.7 & 98 & 104 & 109.3 & 0 & 0 & 0 & 0 & 441.36 & 448.82 & 402.5 & 411.62 & 3.88 & 4.35 & 3.88 & 4.62 \\
\hline $\mathrm{P} 01$ & 97.7 & 221 & 300 & 310 & 3.78 & 3.93 & 4.04 & 4.6 & 481.45 & 516.85 & 496.18 & 502.79 & 3.31 & 5.73 & 5.51 & 6.13 \\
\hline $\mathrm{P} 03$ & 130 & 99.3 & 134.3 & 137 & 0 & 0 & 0 & 0 & 458.16 & 468.33 & 394.61 & 414.37 & 5.83 & 5.64 & 3.91 & 4.76 \\
\hline PI 419017 & 220 & 126.7 & 223 & 233.7 & 0 & 0 & 0 & 0 & 434.74 & 533.01 & 461.83 & 466.37 & 2.04 & 6.18 & 3.69 & 4.2 \\
\hline PI 426169 & 294.3 & 316.7 & 342.7 & 347.3 & 0 & 0 & 0 & 0 & 424.94 & 425.67 & 440.73 & 451.41 & 1.74 & 1.75 & 4.35 & 5.09 \\
\hline Pingwang1 & 46.3 & 167.3 & 252.7 & 286.7 & 3.57 & 4.34 & 4.12 & 4.62 & 383.53 & 461.3 & 397.29 & 404.67 & 1.47 & 5.54 & 0.34 & 0.74 \\
\hline Pingwang2 & 99 & 213.7 & 239.3 & 246.7 & 0 & 0 & 0 & 0 & 428.41 & 441.82 & 393.66 & 398.48 & 5.65 & 4.68 & 4.21 & 4.82 \\
\hline $\mathrm{PO} 2$ & 27.7 & 158.7 & 192.3 & 203.3 & 4.36 & 4.74 & 4.57 & 5.02 & 452.9 & 487.75 & 406.85 & 411.82 & 5.26 & 6.2 & 1.62 & 2.23 \\
\hline Poinsett 76 & 191.3 & 268.7 & 177.7 & 183.3 & 4.69 & 4.68 & 4.5 & 5.44 & 501.68 & 551.63 & 493.82 & 502.31 & 5.89 & 7.56 & 4.62 & 5.22 \\
\hline Poinsett 97 & 183.3 & 202.3 & 196 & 202.7 & 4.12 & 4.3 & 4.23 & 5.16 & 511.91 & 533.59 & 507.42 & 518.23 & 3.3 & 6.45 & 5.76 & 6.39 \\
\hline Shuchunmeiya & 80 & 88.7 & 91.7 & 103.3 & 0 & 0 & 0 & 0 & 510.81 & 483.94 & 432.94 & 438.75 & 6.27 & 4.33 & 4.07 & 4.79 \\
\hline Wynia1 & 126 & 143.3 & 75 & 73.3 & 0 & 0 & 0 & 0 & 438.67 & 439.94 & 541.76 & 551.64 & 5.11 & 5.13 & 3.96 & 4.59 \\
\hline Xintaimici & 333.3 & 251 & 357.7 & 366.7 & 0 & 0 & 0 & 0 & 431.56 & 422.19 & 329.74 & 345.05 & 4.88 & 4.83 & 1.53 & 2.27 \\
\hline Xishuangbannal & 350.7 & 343.3 & 241.3 & 237.3 & 4.07 & 4.15 & 4.18 & 4.69 & 420.09 & 428.52 & 391.83 & 398.84 & 5.63 & 5.75 & 4.5 & 5.11 \\
\hline Xishuangbanna2 & 278.3 & 250.7 & 388 & 420 & 4.24 & 4.45 & 4.23 & 4.66 & 421.6 & 430.85 & 401.28 & 414.74 & 0.3 & 4.55 & 3.42 & 3.99 \\
\hline Xishuangbanna3 & 233.3 & 342.3 & 300.3 & 323.3 & 3.75 & 4.11 & 3.91 & 4.5 & 423.24 & 437.45 & 377.69 & 387.93 & 1.82 & 4.63 & 3.93 & 6.15 \\
\hline Xishuangbanna4 & 136.7 & 243 & 94.7 & 100 & 4.34 & 4.44 & 3.49 & 3.94 & 411.37 & 408.85 & 406.05 & 410.9 & 8.06 & 4.44 & 4.08 & 4.68 \\
\hline
\end{tabular}

myristic acid as shown in Table 1 . Table 4 illustrates interaction means for 2013 and 2014 during spring and autumn as derived from the two-way ANOVA. In Table 4 we observe that cultivars with consistently high seed numbers throughout the four seasons were National Pickling, Xishuangbanna 2, Beijingxiaoci, and Xintaimici. The cultivars with the highest seed oil quantities in all the four seasons were Hazerd, Amir, Beijingxiaoci, CC3b, and Marketmore 2000. Consistently high linoleic was in 'Erzaozi', 'Hazerd', 'Pingwang 2', and 'PO2' throughout the four seasons. In all the seasons oleic was highest in 'JC3', 'Beit Alpha', 'P01', 'CC3b', and 'Beijingxiaoci'. Cultivars with consistently high palmitic were $627 \mathrm{G}$, Poinsett 97, CC3a, PO2, and Lubao. 'EC5 Green', 'Shuchunmeiya', 'PO3', and ' $\mathrm{CC} 3 \mathrm{~b}$ ' had consistently high stearic in all the four seasons.

Cultivar and season interaction means are shown in Table 5, with arrows showing the highest means in each variable. To further separate and get the most significant differences, the season means were compared pairwise using the bonferroni test as shown in Table 6 . The pairwise comparison showed that in
Spring and Autumn 2013 and 2014, the means were significantly different with exception of myristic, arachidic and behenic. In spring, cucumbers had higher oil content in addition to high palmitic, palmitoleic, stearic, oleic, eicosenoic, and lignoceric fatty acids while in autumn there were more seeds, higher linoleic, linolenic, and other fatty acids.

\section{Discussion}

In previous studies the seed oil contents in cucumber cultivars showed wide ranges. For instance; 33.2\% (Matthaus et al., 2003), 41.7\% (Lal et al., 1983), and 25.85\% (Mariod et al., 2009). This implies that the seed oil content is influenced by the type of cultivar. This is consistent with our results which showed significant seed oil variation within cultivars. The detected fatty acids were linoleic, palmitic, oleic, stearic, linolenic, behenic, arachidic, lignoceric, eicosenoic, palmitoleic, myristic, and other fatty acids. Like in the seed oil, the fatty acid content also ranged widely within the cultivars. A previous study by Matthaus et al. (2003) detected similar fatty acids as 
Table 4. Continued

\begin{tabular}{|c|c|c|c|c|c|c|c|c|c|c|c|c|c|c|c|c|c|c|}
\hline \multirow[b]{4}{*}{ Cultivar or species } & \multicolumn{18}{|c|}{ ction means for season and cultivar for seed number, oil content, and fatty acids $(\mathrm{mg} / 100 \mathrm{~g} \text { dry wt })^{2}$} \\
\hline & \multicolumn{4}{|c|}{ C18:0 } & \multicolumn{4}{|c|}{ C18:1 } & \multicolumn{4}{|c|}{ C18:2 } & \multicolumn{4}{|c|}{ C18:3 } & \multirow{2}{*}{\multicolumn{2}{|c|}{$\begin{array}{c}\text { C20:0 } \\
\text { Spring }\end{array}$}} \\
\hline & \multicolumn{2}{|c|}{ Spring } & \multicolumn{2}{|c|}{ Autumn } & \multicolumn{2}{|c|}{ Spring } & \multicolumn{2}{|c|}{ Autumn } & \multicolumn{2}{|c|}{ Spring } & \multicolumn{2}{|c|}{ Autumn } & \multicolumn{2}{|c|}{ Spring } & $\mathrm{Au}$ & $\mathrm{mnn}$ & & \\
\hline & 2013 & 2014 & 2013 & 2014 & 2013 & 2014 & 2013 & 2014 & 2013 & 2014 & 2013 & 2014 & 2013 & 2014 & 2013 & 2014 & 2013 & 2014 \\
\hline $627 \mathrm{G}$ & 275.53 & 270.43 & 201.4 & 205.73 & 885.1 & 431.49 & 285.27 & 306.73 & 1689.7 & 2273.6 & 2436.68 & 2453.58 & 16.93 & 26.64 & 23.62 & 26.66 & 11.17 & 4.03 \\
\hline 8419 & 301.19 & 313.36 & 177.11 & 179.3 & 653.67 & 675.23 & 228.79 & 241.03 & 1758.8 & 1795.6 & 2292.53 & 2319.99 & 13.86 & 29.08 & 21.02 & 27.04 & 9.93 & 8.76 \\
\hline Aidi & 43.85 & 247.46 & 218.77 & 224.36 & 408.55 & 432.83 & 361.35 & 284.8 & 2294.3 & 2079.2 & 2250.29 & 2287.91 & 24.02 & 26.75 & 20.64 & 25.89 & 8.6 & 4.01 \\
\hline Amir & 25.5 & 243.43 & 210.95 & 214.8 & 571.57 & 524.89 & 365.76 & 387.26 & 2207 & 2074.7 & 2392.13 & 2426.66 & 22.67 & 33.89 & 19.22 & 22.29 & 9.7 & 5.53 \\
\hline Baiyu No.2 & 247.49 & 177.54 & 240.17 & 243.48 & 534.51 & 549.6 & 353.82 & 301.24 & 1994.2 & 1909.2 & 2514.67 & 2535.96 & 18.94 & 30.29 & 23.67 & 28.7 & 8.98 & 8.03 \\
\hline Beijingxiaoci & 290.04 & 274.89 & 230.94 & 234.81 & 748.29 & 607.12 & 354.31 & 369.62 & 1886.5 & 2264.3 & 2272.6 & 2294.58 & 16.31 & 33.5 & 17.71 & 20.73 & 12.71 & 5.65 \\
\hline Beit Alpha & 52.45 & 260.96 & 233.03 & 237.41 & 670.76 & 611.49 & 411.79 & 434.25 & 2147.8 & 2061.6 & 2222.92 & 2261.14 & 15.59 & 26.12 & 19.17 & 22.28 & 11.29 & 9.19 \\
\hline BoothbylsBlonde & 281.41 & 142.09 & 141.67 & 144.81 & 615.45 & 418.58 & 208.42 & 221.11 & 1618.8 & 1951.9 & 2361.03 & 2393.87 & 12.57 & 34.91 & 41.67 & 47.8 & 9.53 & 14.61 \\
\hline Cucumis anguria & 3.95 & 163.41 & 76.29 & 81.47 & 154.18 & 228.95 & 86.8 & 102.01 & 1608.2 & 1747 & 1582.24 & 1601.09 & 9.97 & 19.56 & 20.33 & 24.38 & 5.06 & 5.89 \\
\hline $\mathrm{CC} 3 \mathrm{a}$ & 263.04 & 276.52 & 271.19 & 276.59 & 505.05 & 722.85 & 418.3 & 433.92 & 2099.6 & 1868.2 & 2162.21 & 2185.4 & 11.67 & 57.03 & 20.85 & 24.88 & 9.13 & 9.78 \\
\hline $\mathrm{CC} 3 \mathrm{~b}$ & 266.07 & 318.77 & 275.19 & 280.16 & 604.11 & 689.69 & 400.21 & 411.6 & 2053.7 & 2275.4 & 2262.3 & 2283.22 & 20.85 & 29.82 & 23.29 & 28.38 & 10.48 & 9.55 \\
\hline Cerified organic & 207.45 & 168.89 & 130.08 & 137.17 & 671.19 & 419.39 & 175.91 & 211.61 & 1850.2 & 1744.5 & 2272.48 & 2298.9 & 25.43 & 32.22 & 32.73 & 38.07 & 11.43 & 4.24 \\
\hline Changchunmici & 207.86 & 191.18 & 195.45 & 200.5 & 304.88 & 383.04 & 306.32 & 321.41 & 2214.7 & 2265 & 2116.96 & 2137.56 & 18.66 & 30.33 & 18.66 & 22.67 & 7.57 & 5.73 \\
\hline Chaoy & 30.03 & 343.06 & 269.79 & 275.58 & 456.33 & 889.79 & 299.74 & 297.7 & 2090 & 2004.7 & 2389.33 & 2407.44 & 10.03 & 36.66 & 23.06 & 28.12 & 8.71 & 14.51 \\
\hline Cuiyu No.8 & 252.83 & 196.13 & 199.48 & 206.19 & 476.13 & 719.42 & 249.7 & 237.07 & 2213.8 & 1710.1 & 1859.24 & 1888.96 & 21.79 & 33.46 & 15.65 & 21.76 & 9.61 & 10.87 \\
\hline EC5 & 202.69 & 258.24 & 152.35 & 158.21 & 494.47 & 214.54 & 185.53 & 196.53 & 2364.6 & 2355.8 & 2186.33 & 2213.3 & 14.37 & 20.56 & 42.41 & 45.98 & 9.01 & 10.39 \\
\hline EC5 Green & 214.39 & 345.19 & 302.46 & 308.44 & 503.76 & 860.88 & 412.56 & 279.39 & 2047.8 & 1813.1 & 2047.08 & 2069.4 & 15.62 & 27.51 & 25.8 & 31.88 & 9.04 & 5.36 \\
\hline EC $5 \mathrm{Gl}$ & 214.39 & 220.26 & 249.07 & 255.55 & 503.76 & 529.21 & 330.51 & 276.38 & 2047.8 & 1914.5 & 2171.52 & 2200.48 & 15.62 & 27.69 & 25 & 29.15 & 9.04 & 4.97 \\
\hline EC5 Yellow & 4.39 & 166.93 & 112.05 & 118.12 & 503.76 & 358.36 & 196.5 & 260.47 & 2047.8 & 1972.8 & 2169.57 & 2206.21 & 15.62 & 29.76 & 34.74 & 39.74 & 9.04 & 5.16 \\
\hline Erzaozi & 14.25 & 322.89 & 216.03 & 219.99 & 368.5 & 473.46 & 273.23 & 303.39 & 2370.3 & 2238.4 & 2605.52 & 2628.07 & 26.8 & 27.62 & 21 & 26.09 & 7.94 & 6.12 \\
\hline Hazerd & 7.02 & 255.94 & 222.31 & 229.12 & 346.5 & 595.87 & 350.57 & 329.07 & 1919.2 & 2310.8 & 2747.91 & 2778.07 & 9.45 & 37.53 & 22.66 & 26.78 & 7.21 & 5.6 \\
\hline HH1-8-1-2 & 5.65 & 298.13 & 195.07 & 199.36 & 589.92 & 654.13 & 269.99 & 284.38 & 1846.3 & 2047.6 & 2272.68 & 2291.96 & 21.19 & 34.46 & 24.47 & 29.5 & 9.79 & 11.48 \\
\hline Home & 17.65 & 300.76 & 225.32 & 228.87 & 819 & 594.99 & 268.43 & 285.08 & 1731.2 & 1973.8 & 2528.61 & 2552.77 & 17.86 & 32.57 & 29.38 & 32.46 & 11.9 & 4.39 \\
\hline Indetermi & 227.6 & 244.87 & 171.11 & 179.23 & 379.59 & 429.96 & 216.05 & 270.87 & 2106.7 & 1825.4 & 2219.97 & 2262.82 & 24.77 & 22.72 & 24 & 28.29 & 8.95 & 9.79 \\
\hline $\mathrm{JC} 1$ & 236.14 & 286.13 & 208.55 & 211.38 & 441.22 & 531.77 & 391.19 & 404.72 & 2114.6 & 2066.6 & 2208.57 & 2239.26 & 15.96 & 27.93 & 26.86 & 32.3 & 10.22 & 4.54 \\
\hline $\mathrm{JC} 3$ & 252.16 & 260.96 & 191.13 & 193.53 & 673.91 & 668.67 & 436.69 & 449.56 & 1628.8 & 1933.1 & 2067.34 & 2093.63 & 18.37 & 26.51 & 21.69 & 27.74 & 10.86 & 4.44 \\
\hline L8 & 8.72 & 190.42 & 189.07 & 192.3 & 849.28 & 435.95 & 262.11 & 282.4 & 1712.8 & 1989.1 & 2086.75 & 2114.05 & 17.62 & 27.61 & 27.53 & 30.56 & 12.24 & 5.65 \\
\hline Lubao & 20.1 & 220.1 & 222.48 & 225.74 & 574.82 & 574.82 & 222.09 & 247.57 & 1316.6 & 1316.6 & 2005.54 & 2018.91 & 24.6 & 24.6 & 24.98 & 30.01 & 8.64 & 8.64 \\
\hline Marketı & 46.7 & 245 & 185.23 & 189.23 & 693.19 & 719.72 & 261.69 & 282.95 & 2116.2 & 2018.6 & 2470.93 & 2498.45 & 20.72 & 60.8 & 30.78 & 35.92 & 11.5 & 8.01 \\
\hline Nation & 5 & 277.6 & 243.65 & 250.74 & 462.63 & 633.77 & 315.68 & 329.68 & 2084.7 & 1969.8 & 2297.44 & 2336.57 & 12.51 & 29.66 & 31.25 & 36.65 & 9.5 & 10.99 \\
\hline Oumeijia & 7.8 & 304.01 & 207.29 & 212.4 & 425.39 & 573.76 & 355.66 & 375.32 & 2020.5 & 1902.7 & 2092.46 & 2131.85 & 18.78 & 28.11 & 16.97 & 20.14 & 9.17 & 5.69 \\
\hline P01 & 6.88 & 286.98 & 257.09 & 261.75 & 610.01 & 604.96 & 434.45 & 456.56 & 1961.4 & 2044.3 & 2404.35 & 2423.52 & 14.78 & 32.31 & 21.19 & 24.91 & 10.19 & 7.03 \\
\hline P03 & 251.27 & 254.78 & 273.18 & 285.3 & 522.23 & 603.64 & 363.86 & 393.18 & 2219 & 2096.6 & 2055.21 & 2159.11 & 30.91 & 29.6 & 17.21 & 21.89 & 10.11 & 4.93 \\
\hline PI 419017 & 210.23 & 242.03 & 177.65 & 183.86 & 372.42 & 596.61 & 228.38 & 274.35 & 1895.2 & 2158.6 & 2299.06 & 2315.74 & 17.77 & 29.07 & 35.31 & 39.35 & 8.64 & 4.36 \\
\hline PI 426169 & 244.47 & 244.89 & 271 & 227.63 & 436.46 & 437.22 & 269.14 & 283.77 & 1897.5 & 1900.8 & 2281.43 & 2318.43 & 19.34 & 19.38 & 20.75 & 24.96 & 8.75 & 8.76 \\
\hline Pingwang1 & 7.79 & 184.64 & 182.56 & 185.72 & 297.8 & 533.58 & 269.83 & 285.07 & 2025 & 2320.4 & 2222.81 & 2248.17 & 21.6 & 28.31 & 17.96 & 20.98 & 8.43 & 10 \\
\hline Pingwang2 & 9.75 & 215.45 & 228.64 & 233.11 & 347.61 & 326.42 & 305.89 & 322.86 & 2309 & 2472.7 & 2317.4 & 2338.23 & 16.16 & 27.47 & 19.28 & 22.32 & 7.23 & 19.79 \\
\hline $\mathrm{PO} 2$ & 9.98 & 246.49 & 207.28 & 211.79 & 451.22 & 542.5 & 302.48 & 324.2 & 2120.4 & 2251.8 & 2489.95 & 2510.74 & 20.14 & 32.24 & 20.05 & 23.1 & 8.51 & 7.54 \\
\hline Poins & 4.9 & 289.13 & 186.82 & 190.01 & 564.1 & 708.08 & 234.93 & 245.17 & 2188.8 & 1916.7 & 2444.44 & 2456.88 & 23.47 & 33.47 & 31.21 & 36.24 & 9.74 & 5.04 \\
\hline Poinsett 97 & 9.53 & 300.5 & 215.25 & 220.11 & 378.69 & 654.08 & 302.74 & 314.42 & 2211.4 & 1965.6 & 2381.83 & 2405.02 & 15.11 & 32.99 & 23.48 & 28.61 & 9.04 & 4.66 \\
\hline Shuchunmeiya & 37.74 & 319.5 & 235.78 & 240.31 & 572.6 & 591.64 & 278.26 & 296.08 & 2136.7 & 2087 & 2437.27 & 2471.13 & 18.22 & 35.82 & 23.7 & 26.86 & 10.62 & 4.69 \\
\hline Wynial & 230.02 & 230.69 & 224.26 & 230.87 & 720.34 & 722.42 & 237.68 & 249.38 & 1591.2 & 1595.8 & 2187.92 & 2218.58 & 14.62 & 14.67 & 49.03 & 53.38 & 11.15 & 11.18 \\
\hline Xintaimici & 212.03 & 223.93 & 170.5 & 179.29 & 341.3 & 556.71 & 261.27 & 284.2 & 2316.9 & 2068.4 & 1995.88 & 2085.27 & 22.15 & 29.34 & 17.65 & 24.26 & 7.61 & 15.19 \\
\hline Xishuangbannal & 209.09 & 213.3 & 159.37 & 162.05 & 495.54 & 505.48 & 172.98 & 183.59 & 1901.3 & 1939.7 & 2417.94 & 2435.05 & 8.46 & 8.62 & 14.36 & 17.05 & 8.87 & 9.05 \\
\hline Xishuan: & 9.87 & 271.96 & 181.66 & 188.37 & 377.62 & 420.8 & 224.66 & 245.2 & 1883.9 & 1937.5 & 2129.91 & 2189.23 & 9.39 & 25.83 & 31.01 & 34.17 & 8.07 & 3.6 \\
\hline Xishuangbanna3 & 273.15 & 259.31 & 189.87 & 194.33 & 548.12 & 401.34 & 171.48 & 182.55 & 1552.2 & 1949.6 & 2164.92 & 2189.45 & 16.34 & 22.11 & 37.74 & 43.47 & 9.81 & 3.79 \\
\hline Xishuangbanna4 & 144.11 & 207.6 & 115.01 & 116.96 & 356.4 & 317.48 & 157.31 & 167.25 & 2043.1 & 2121.6 & 1745.78 & 1760.1 & 15.3 & 21.26 & 36.88 & 38.87 & 10.03 & 4.44 \\
\hline
\end{tabular}

well as vaccenic acid (C18:1n-7). Mariod et al. (2009) detected arachidonic which we did not detect. Another study detected similar fatty acids in one cucumber cultivar but did not detect myristic acid (Achu et al., 2006). Our results showed varying fatty acid profiles in different cultivars. Similar studies on other crops have shown that fatty acid profiles are not wholly similar in all cultivars of the same crop. For example, in seeds of bitter gourd [Momordica charantia (Ali et al., 2008)], pumpkin [Cucurbita pepo (Younis et al., 2000)], jute [Corchorus olitorius (Siriamornpun et al., 2006)], and rape [Brassica napus (Novickiene et al., 2010)] the fatty acid profiles were different. This can possibly explain why other studies that used different cultivars got varying fatty acid profiles as in our case where myristic and lignoceric were not detected in all cultivars and in some seasons since the contents were too low to be detected.

This study detected lignoceric acid that has not been reported before in cucumber. In an Uruguayan cucumber cultivar, fatty acids such as myristoleic (C14:1), caprylic
(C8:0), capric (C10:0), and lauric (C12:0) as well as other unknown fatty acids were reported by Grompone (1988). This later report could explain why some cultivars had high amounts of other fatty acids, and thus supporting the findings that genotypic peculiarities partly govern fatty acid composition (Novickiene et al., 2010). This is further supported by the consistently low seed oil and fatty acids in C. anguria throughout all the seasons in our study.

The present results indicate that seed oil content and composition are primarily determined by the cultivar genotype due to similarities in related cultivars. Seed numbers were also cultivar dependent and did not affect seed oil content or composition. However, a cultivar with a high seed number coupled with high oil content will give higher oil yields. According to the data in this study many cultivars had sufficient oil content as well as seed numbers per fruit. Oil content and fatty acid profiles in cucumber are similar to those in other edible oils such as $H$. annuus oil which has a mean of about $37 \%$ (Pérez-Vich et al., 1998). 
Table 4. Continued

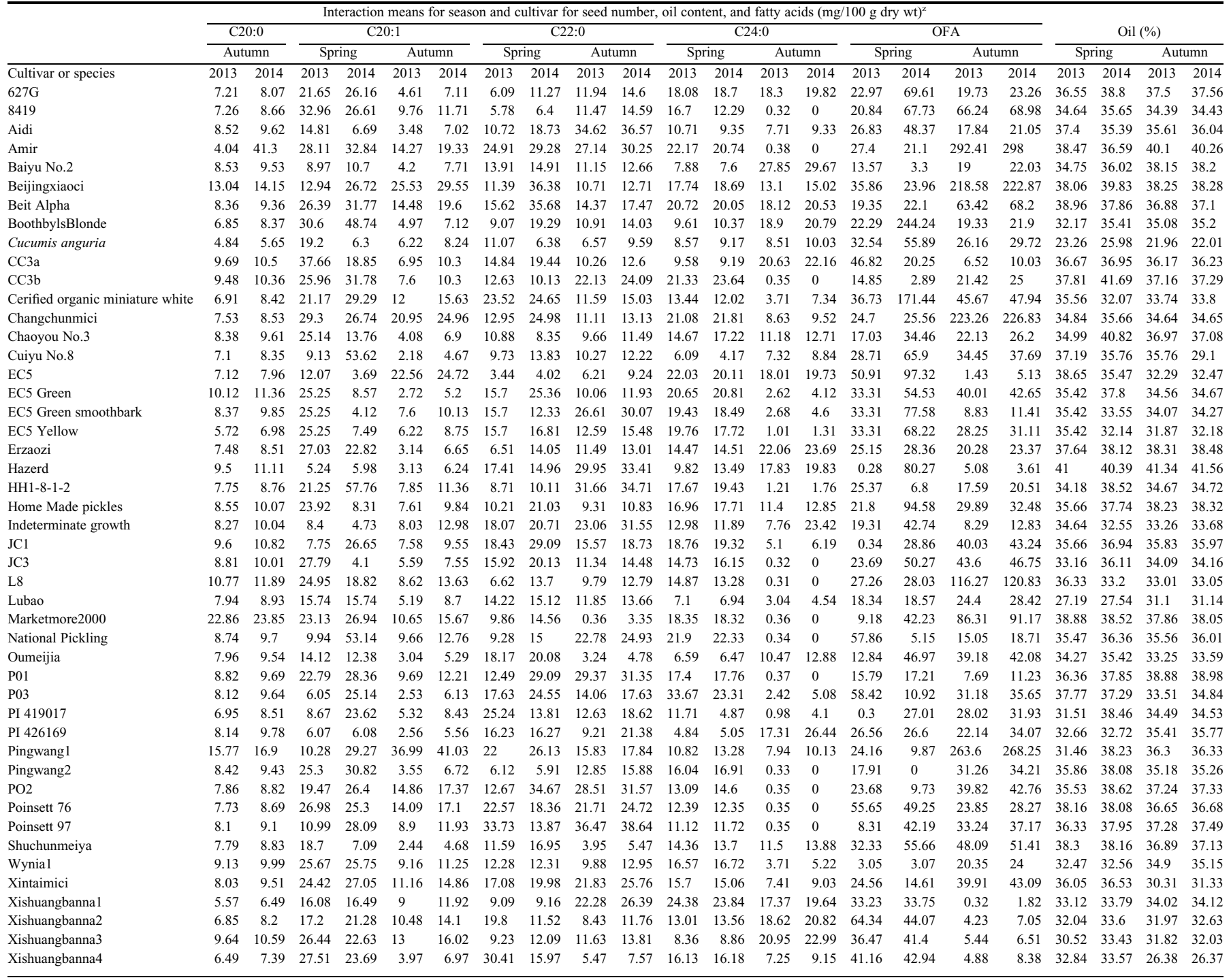

${ }^{\mathrm{z}} \mathrm{C} 14: 0=$ myristic, $\mathrm{C} 16: 0=$ palmitic, $\mathrm{C} 16: 1=$ palmitoleic, $\mathrm{C} 18: 0=$ stearic, $\mathrm{C} 18: 1=$ oleic, $\mathrm{C} 18: 2=1$ linoleic, $\mathrm{C} 18: 3=$ linolenic, $\mathrm{C} 20: 0=$ arachidic, $\mathrm{C} 20: 1=$ eicosenoic, $\mathrm{C} 22: 0=$ behenic, $\mathrm{C} 24: 0=$ lignoceric, $\mathrm{OFA}=$ other fatty acids.

The cultivar's genotype influences oil content and fatty acid composition. This is because a genotype is dependent on genes and enzymes that control synthesis of different fatty acids that in turn decrease or increase the composition of fatty acids. This is well demonstrated in Table 2 where similar cultivars such as Xishuangbanna 1 and Xishuangbanna 2, Xishuangbanna 3 and
Xishuangbanna 4, PI 419017 and PI 426169, and Poinsett 76 and Poinsett 97 had very similar oil and fatty acid quantities. However, this was not always the case for all similar cultivars such as $\mathrm{CC} 3 \mathrm{a}$ and $\mathrm{CC} 3 \mathrm{~b}$; $\mathrm{PO} 1, \mathrm{PO} 2$, and $\mathrm{PO} 3$; and $\mathrm{JC} 1$ and $\mathrm{JC} 3$, which were slightly different possibly due to breeding that affected the genes controlling the seed oil biosynthesis.

Table 5. Seasonal mean variation for seed number, oil content, and fatty acids in cucumber cultivars in Spring and Autumn 2013 and 2014.

\begin{tabular}{lrrrrrrrrrrrrrr}
\hline & Seeds & \multicolumn{10}{c}{ Fatty acids (mg/100 g dry wt) } \\
\cline { 3 - 12 } Season & (no.) & C14:0 & C16:0 & C16:1 & C18:0 & C18:1 & C18:2 & C18:3 & C20:0 & C20:1 & C22:0 & C24:0 & OFA & Oil \\
\hline Spring 2013 & 182 & $\uparrow 1.79$ & $\uparrow 452.2$ & $\uparrow 4.64$ & $\uparrow 236$ & $\uparrow 516.6$ & 1988.4 & 17.72 & $\uparrow 9.46$ & $\uparrow 18.65$ & 13.88 & $\uparrow 15.19$ & 26.57 & $\uparrow 35.1$ \\
Autumn 2013 & $\uparrow 222$ & 1.77 & 434.2 & 4.02 & 205 & 286.6 & $\uparrow 2245.6$ & $\uparrow 25.27$ & 9.29 & 8.9 & $\uparrow 15.19$ & 8.23 & $\uparrow 47.33$ & 34.8 \\
Spring 2014 & 203 & 1.83 & $\uparrow 462.7$ & $\uparrow 5.34$ & $\uparrow 251$ & $\uparrow 546.3$ & 2010.7 & 29.54 & 9.4 & $\uparrow 24.78$ & $\uparrow 18.69$ & $\uparrow 14.89$ & 44.16 & $\uparrow 36$ \\
Autumn 2014 & $\uparrow 229$ & $\uparrow 2.06$ & 442.1 & 4.66 & 209 & 296.3 & $\uparrow 2275.3$ & $\uparrow 29.64$ & $\uparrow 10.46$ & 12.03 & 18.2 & 9.94 & $\uparrow 50.85$ & 35
\end{tabular}

${ }^{\mathrm{z}} \mathrm{C} 14: 0=$ myristic, C16:0 = palmitic, C16:1 = palmitoleic, C18:0 = stearic, C18:1 = oleic, C18:2 = linoleic, C18:3 = linolenic, C20:0 = arachidic, $\mathrm{C} 20: 1=$ eicosenoic, $\mathrm{C} 22: 0=$ behenic, $\mathrm{C} 24: 0=$ lignoceric, $\mathrm{OFA}=$ other fatty acids, $\mathrm{S}=$ season.

$\uparrow=$ indicator for the higher mean in each season. 


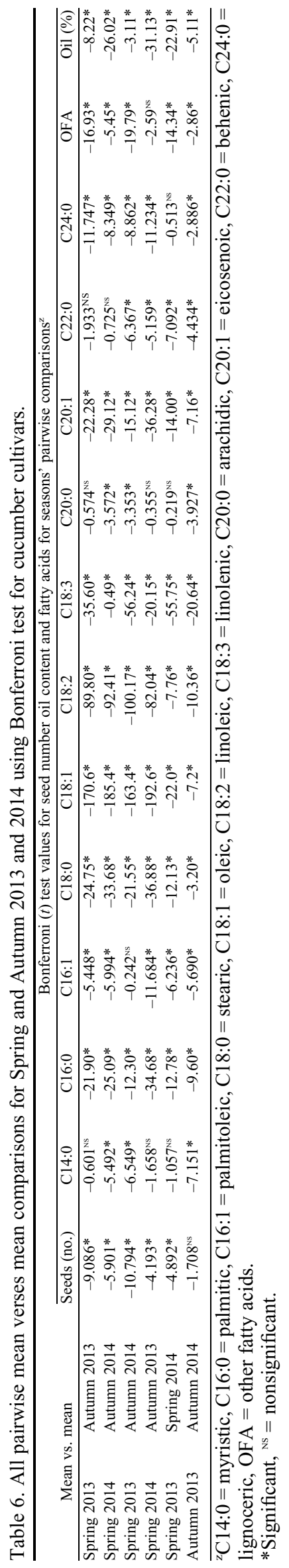

Our results indicated that linoleic had a strong negative relation with oleic as well as a weak negative relation with stearic which agrees with those of other crops where increased oleic reduced linoleic and stearic percentages in seed oil crops (Izquierdo et al., 2013) as shown in Table 3.

Seed oil content increased slightly in spring which was also true for Glycine max, where high temperatures had little or no effect on oil content in the seeds (Ojo et al., 2002). However, the composition of the seed oil fatty acids were affected by seasonal changes as illustrated in Table 5. High temperatures have been found to alter seed oil composition by increasing oleic and decreasing linoleic and linolenic concentrations (Bellaloui et al., 2013). High temperatures during seed filling increased palmitic and oleic percentages and reduced stearic and linoleic percentages in $H$. annuus, suggesting some modification of enzymatic activities (Izquierdo et al., 2013) as a possible explanation for seasonal variation in fatty acid quantities.

The spring season plants encountered high temperatures during the seed filling stage hence the increased palmitic, palmitoleic, stearic, oleic, eicosenoic, and lignoceric fatty acids. High temperatures of $40 / 33{ }^{\circ} \mathrm{C}$ (day/night) resulted in higher palmitic and lower stearic acid (Bellaloui et al., 2013). Palmitic and stearic did not show any correlation with temperatures in our work. When the temperatures in Nanjing were 40/ $33{ }^{\circ} \mathrm{C}$ (day/night) in July, the cucumbers had already been harvested, thus missing the high summer temperatures that could have influenced the fatty acid compositions.

Low temperatures reduced oleic quantity (Pritchard et al., 2000) due to the activity of microsomal oleoyl phosphatidylcholine desaturase being enhanced at low temperatures of between 10 and $20{ }^{\circ} \mathrm{C}$. This later observation was explained as being due to increased enzyme synthesis, increasing linnoleate quantities (Garcés et al., 1992). Autumn cultivars had more seed numbers as well as increased quantities of linoleic, linolenic and other fatty acids, and this could be due to lower temperatures during seed filling that occurred when temperatures were decreasing toward winter. This findings agree with results reported by Martínez-Rivas et al. (2003) where linoleic increased at " $25{ }^{\circ} \mathrm{C}$ day $/ 15{ }^{\circ} \mathrm{C}$ night" temperature due to increased activity of microsomal oleate desaturase (FAD2).

The main environmental factor affecting fatty acid composition is whether temperatures are high or low following the onset of flowering (Baux et al., 2008), hence determining the quantity of fatty acids in the seed. An increase in temperature from 10 to $40{ }^{\circ} \mathrm{C}$ resulted in an increased synthesis of oleic and a decreased synthesis of linoleic and linolenic in $G$. $\max , B$. napus, and $H$. annuus resulting in more monounsaturated oils and less polyunsaturated oils (Schulte et al., 2013).

The results of our study show that the seed oil content in cucumber is sufficient for commercial extraction. The oil content and fatty acid composition is comparable to that of other commercial oils and can therefore be exploited as edible oil, nutraceutical and cosmetic ingredient in addition to other industrial uses. Cucumber cultivars have a high variation in oil content and fatty acid compositions and are therefore suitable for genetic engineering to produce different novel fatty acids for specialized uses.

Cucumber seed oils have similar characteristics to other commercial seed oils, implying that methods used to increase oil content and quality in other vegetable oils can also be successfully applied in cucumber. Seed oil and fatty acid synthesis is a complex interaction between environmental conditions, seed 
growth, and oil synthesis dynamics (Echarte et al., 2013), and further research in a climate controlled environment can be done to further validate the results obtained.

We conclude that there is a highly significant variation both in oil content ( $41.07 \%$ to $29.24 \%$ ) and fatty acid composition in the cucumber cultivars that can be used for improvement. The high oil content coupled with the reasonably high concentration of fatty acids makes the seed oil suitable for further development and utilization as a food supplement, cosmetic, pharmaceutical product, insecticide, and other novel industrial uses. Consequently, the information gotten from this study on seed number, oil content, fatty acid composition, and seasonal variation, which was for instance very significant in oleic where spring had $546.3 \mathrm{mg} / 100 \mathrm{~g}$ and autumn $296.3 \mathrm{mg} / 100 \mathrm{~g}$, will be useful in future cucumber breeding research and seed oil exploitation for relevant industrial development and economic gains from cucumber-based entrepreneurs.

\section{Literature Cited}

Achu, M.B., E. Fokou, C. Tchiégang, M. Fotso, and M.F. Tchouanguep. 12006. Chemical characteristics and fatty acid composition of Cucurbitaceae oils from Cameroon. Intl. Union Food Sci. Technol. 10:1249-1259.

Achu, M.B., E. Fokou, C. Tchiégang, M. Fotso, and M.F. Tchouanguep. 2008. Atherogenicity of Cucumeropsis mannii and Cucumis sativus oils from Cameroon. African J. Food Sci. 2:021-025.

Ali, A., M.M. Sayeed, A.R. Sultanur, Y. Sarmina, and A.K. Mohal. 2008. Characteristics of seed oils and nutritional compositions of seeds from different varieties of Momordica charantia Linn. cultivated in Bangladesh. Czech J. Food Sci. 26:275-283.

Amir, H., S. Rad, and Z. Peiman. 2012. A comparison of fatty acid compounds in winter and spring rapeseed varieties. Ann. Biol. Res. 3:1408-1414.

Association of Official Agricultural Chemists (AOAC). 1990. Official methods of analysis. 15th ed. Assn. Offic. Anal. Chem., Washington, DC.

Baux, A., T. Hebeisen, and D. Pellet. 2008. Effects of minimal temperatures on low-linolenic rapeseed oil fatty-acid composition. Eur. J. Agron. 29:102-107.

Bellaloui, N., A. Mengistu, and M.K. Abdelmajid. 2013. Effects of genetics and environment on fatty acid stability in soybean seed. Food Nutr. Sci. 4:165-175.

Chaudhari, S.V. 2014. Management of insect pest by using herbal plants extracts. J. Intl. Acad. Res. Multidisciplinary 2:453-459.

Echarte, M.M., L.P. Alejandra, and L.A.N. Aguirrezabal. 2013. Assessment of the critical period for the effect of intercepted solar radiation on sunflower oil fatty acid composition. Field Crops Res. 149:213-222.

Fayyaz-ul-Hasan, and R.A. Ahmad. 2003. Effects of seasonal variations on oil and fatty acid profile of sunflower. Helia 26:159-166.

Garcés, R., C. Sarmiento, and M. Mancha. 1992. Temperature regulation of oleate desaturase in sunflower (Helianthus annuus L.) seeds. Planta 186:461-465.

Ghulam, Q., A. Shahbaz, H. Fayyaz-Ul, and A.M. Cheema. 2006. Oil and fatty acid accumulation in sunflower as influenced by temperature variation. Pak. J. Bot. 38:1137-1147.

Grompone, M.A. 1988. Chemical evaluation of Uruguayan Cucurbitaceae seeds as potential sources of vegetable oil. Fat Sci. Technol. 90:487-490.

Heidari, H., M. Kamalinejad, and M.R. Eskandari. 2012. Hepatoprotective activity of Cucumis sativus against cumene hydroperoxide induced-oxidative stress. Res. Pharm. Sci. 7:S936-S939.

Izquierdo, N.G., L.A.N. Aguirrezábal, E. Martínez-Force, R. Garcés, V. Paccapelo, F. Andrade, R. Reid, and A. Zambelli. 2013. Effect of growth temperature on the high stearic and high stearic-high oleic sunflower traits. Crop Pasture Sci. 64:18-25.
Lal, B.M., N. Datta, and T.R. Madaan. 1983. A study of kernel oils of some cultivated Cucurbits. Plant Foods Hum. Nutr. 32:83-85.

Magin, P.J., J. Adams, C.D. Pond, and W. Smith. 2006. Topical and oral CAM in acne: A review of the empirical evidence and a consideration of its context. Complement. Ther. Med. 14:62-76.

Mallik, J., P. Das, and S. Das. 2013. Pharmacological activity of Cucumis sativus L.: A complete overview. Asian J. Pharmaceutical Res. Dev. 1:1-6.

Mariod, A.A., Y.M. Ahmed, B. Mattha, G. Khaleel, A. Siddig, A.M. Gabra, and S.I. Abdelwahab. 2009. A comparative study of the properties of six sudanese cucurbit seeds and seed oils. J. Amer. Oil Chem. Soc. 86:1181-1188.

Martínez-Rivas, J.M., A. Sánchez-García, M.D. Sicardo, M.T. GarcíaDíaz, and M. Mancha. 2003. Oxygen-independent temperature regulation of the microsomal oleate desaturase (FAD2) activity in developing sunflower (Helianthus annuus) seeds. Physiol. Plant. 117:179-185.

Matthaus, B., K. Vosmann, L.Q. Pham, and K. Aitzetmüller. 2003. FA and tocopherol composition of Vietnamese oil seeds. J. Amer. Oil Chem. Soc. 80:1013-1020.

Mootoosamy, A. and M.M. Fawzi. 2014. Ethnomedicinal application of native remedies used against diabetes and related complications in Mauritius. J. Ethnopharmacol. 151:413-444.

Mostafa, M., H. Hemayet, M.A. Hossain, K.B. Pizush, and H.M. Zahurul. 2012. Insecticidal activity of plant extracts against Tribolium castaneum Herbst. J. Adv. Sci. Res. 3:80-84.

Muller, R.H., R.D. Petersen, A. Hommoss, and J. Pardeike. 2007. Nanostructured lipid carriers (NLC) in cosmetic dermal products. Adv. Drug Deliv. Rev. 59:522-530.

Ng, T.J. 1993. New opportunities in the Cucurbitaceae, p. 538546. In: J. Janick and J.E. Simon (eds.). New crops. Wiley, New York, NY.

Novickiene, L., V. Gavelienè, L. Miliuvienė, D. Kazlauskiene, and L.P. Škyte. 2010. Comparison of winter oilseed rape varieties: Cold acclimation, seed yield and quality. Zemdirbyste Agr. 97:77-86.

Ojo, D.K., M.A. Adebisi, and B.O. Tijani. 2002. Influence of environment on protein and oil contents of soybeans seed (Glycine $\max ($ L.) Merril). Global J. Agr. Sci. 1:27-32.

Pérez-Vich, B., L. Velasco, and J.M. Fernández-Martínez. 1998. Determination of seed oil content and fatty acid composition in sunflower through the analysis of intact seeds, husked seeds, meal and oil by near-infrared reflectance spectroscopy. J. Amer. Oil Chem. Soc. 75:547-555.

Pieroni, A., C.L. Quave, M.L. Villanelli, P. Mangino, G. Sabbatini, L. Santini, T. Boccetti, M. Profili, T. Ciccioli, L.G. Rampa, G. Antonini, C. Girolamini, M. Cecchi, and M. Tomasi. 2004. Ethnopharmacognostic survey on the natural ingredients used in folk cosmetics, cosmeceuticals and remedies for healing skin diseases in the inland Marches, Central-Eastern Italy. J. Ethnopharmacol. 91:331-344.

Pritchard, F.M., H.A. Eagles, R.M. Norton, P.A. Salisbury, and M. Nicolas. 2000. Environmental effects on seed composition of Victorian canola. Austral. J. Exp. Agr. 40:679-685.

Rahman, A.H.M.M., M. Anisuzzaman, F. Ahmed, I.A.K.M. Rafiul, and A.T.M. Naderuzzaman. 2008. Study of nutritive value and medicinal uses of cultivated cucurbits. J. Appl. Sci. Res. 4:555-558.

Rahuman, A.A. and P. Venkatesan. 2008. Larvicidal efficacy of five cucurbitaceous plant leaf extracts against mosquito species. Parasitol. Res. 103:133-139.

Saboo, S.S., P.K. Thorat, G.G. Tapadiya, and S.S. Khadabadi. 2013. Ancient and recent medicinal uses of Cucurbitaceae family. Intl. J. Therapeutic Appl. 9:11-19.

Schulte, L.R., T. Ballard, T. Samarakoon, L. Yao, P. Vadlani, S. Staggenborge, and M. Rezacf. 2013. Increased growing temperature reduces content of polyunsaturated fatty acids in four oilseed crops. Ind. Crops Prod. 51:212-219.

Simopoulos, A.P. 1991. Omega-3 fatty acids in health and disease and in growth and development. Amer. J. Clin. Nutr. 54:438463. 
Siriamornpun, S., L. Duo, Y. Lifeng, K. Wanna, and S. Maitree. 2006. Thai jute seed oil: A potential polyunsaturated fatty acid source. J. Sci. Technol. Nutraceutical Functional Food 28:11-15.

Souri, E., G. Amin, H. Farsam, and T.M. Barazandeh. 2008. Screening of antioxidant activity and phenolic content of 24 medicinal plant extracts. DARU J. Pharmaceutical Sci. 16:83-87.

Sukkasem, C., P. Laosuwan, S. Wonprasaid, and T. Machikowa. 2013. Effects of environmental conditions on oleic acid of sunflower seeds. Intl. J. Chem. Environ. Biol. Sci. 1:395-396.

Tadayyon, B. 2013. The miracle of vegetables: The scientific facts about nutritional properties and medicinal values of vegetables. Random House, London, UK.

Terés, S., G. Barceló-Coblijn, M. Benet, R. Álvarez, R. Bressani, J.E. Halver, and P.V. Escribá. 2008. Oleic acid content is responsible for the reduction in blood pressure induced by olive oil. Proc. Natl. Acad. Sci. USA 105:13811-13816.
Ursin, V.M. 2003. Modification of plant lipids for human health: Development of functional land-based omega-3 fatty acids. J. Nutr. 133:4271-4274.

Van Luijk, M.N. 2004. Cucumis sativus L. plant resources tropical Africa, Wageningen, The Netherlands.

Vermaak, I., G.P.P. Kamatou, B. Komane-Mofokeng, A.M. Viljoen, and K. Beckett. 2011. African seed oils of commercial importance: Cosmetic applications. S. Afr. J. Bot. 77:920-933.

Waterman, E. and B. Lockwood. 2007. Active components and clinical applications of olive oil. Altern. Med. Rev. 12:331-342.

Wright, C.I., L. Van-Buren, C.I. Kroner, and M.M.G. Koning. 2007. Herbal medicines as diuretics: A review of the scientific evidence. J. Ethnopharmacol. 114:1-31.

Yang, S.L. and T.W. Walters. 1992. Ethnobotany and the economic role of the Cucurbitaceae of China. Econ. Bot. 46:349-367.

Younis, Y.M.H., G. Seniat, and S.S. Al-Shihry. 2000. African Cucurbita pepo L.: Properties of seed and variability in fatty acid composition of seed oil. Phytochemistry 54:71-75. 